\title{
CTNND2 Gene
}

National Cancer Institute

\section{Source}

National Cancer Institute. CTNND2 Gene. NCI Thesaurus. Code C82941.

This gene is involved in the regulation of both transcription and signal transduction. 